other place where they can breed. They would in this case have to fly continuously across the lake.

Mr. T. J. Headlee: It was noted in England where flies had come from five miles away.

President Glenn W. Herrick: The next paper will be by $\mathrm{Mr}$. Joseph H. Merrill.

\title{
LIFE-HISTORY AND HABITS OF TWO NEW NEMATODES PARASITIC ON INSECTS
}

By Joseph H. Merrill, Manhattan, Kans.

(Withdrawn for publication elsewhere)

President Glenn W. Herrick: It is interesting to find that there are some nematode forms that seem to be of some use in life.

I did not understand Mr. Merrill to say whether they actually killed the insects.

Mr. J. H. MerRILL: A tent was placed around the trunk of an elm tree so that all emerging insects might be secured for breeding purposes. There were 121 Saperda tridentata which emerged from this tree and were placed in breeding cages, but in no instance did any of these insects deposit eggs. Not only was the vitality of the insects lowered but their natural functions were so interfered with that eggs did not even start to develop within their bodies. The death rate, due to nematode parasitism, was 100 per cent. Several experiments were carried on by placing termites in soil known to contain nematodes. In twelve days all of the termites had died, due to this nematode parasitism.

Mr. Don C. Mote: I would like to inquire whether these nematodes are truly parasitic. I take it from the paper that Mr. Merrill was able to rear them from the egg to the adult stage in cultures. This fact would seem to indicate that they are not necessarily dependent upon taking up their abode in the insects' intestines for their development. Generally nematode parasites attain a certain point in this development outside the host beyond which they cannot go unless they reach their normal habitat within their host.

Mr. J. H. Merrill: These nematodes were found to be parasitic on Saperda tridentata and Leucotermes lucifugus. The nematodes found in S. tridentata were fed in cultures on the macerated bodies of insects, while those found in the termites were fed exclusively on termites as we could casily secure a plentiful supply of these insects.

Mr. Don C. Mote: At what time during the developmental stage did infestation occur? 
Mr. J. H. MerriLl: How and when the nematodes gain entrance into the insects are two questions that are yet to be solved. As the nematodes were found in the intestines of $S$. tridentata it is possible that the nematode eggs may have been taken in with the food. As the nematode in the termites were found in the head and mouth cavity, these may have entered while the worms were still young. Although they could enter when quite small, they could not complete their development within the termite.

President GlenN W. Herrick: Any more questions concerning this paper? If not we will pass to the next paper by Mr. J. W.. Chapman and R. W. Glaser.

\section{FURTHER STUDIES ON WILT OF GIPSY MOTH CATERPIL- LARS ${ }^{1}$}

By J. W. Chapanan and R. W. Glaser

\section{INTRODUCTION}

During the past two summers (1914-1915) certain questions in connection with wilt of gipsy moth caterpillars have begun to clarify. The published experimental results obtained during the summer of 1913, while helpful in interpreting many of the phenomena encountered in this interesting problem, nevertheless left much in doubt. Our efforts were renewed during the summer of 1914 with the hope of verifying all of our previous experiments (1913) and of solving some of the questions towards which we had begun to assume a sceptical attitude. Many interesting matters were forcibly impressed upon us: during the course of this study which extended over two seasons. The results obtained in 1914 were discouraging although instructive. In 1915, however, we not only obtained data harmonizing with those of 1913 , but surpassing our expectations by yielding new and interesting results. This work also clearly revealed the inadequacy of some of our methods.

In order that other investigators interested in the polyhedral diseases of insects may be spared many of the tedious difficulties which we encountered we present our work historically, and will attempt to give an account of the methods which must be pursued in order to ensure dependable results. This method of procedure will also have the advantage of placing our new results in a proper light.

${ }^{1}$ Contribution from the U. S. Bureau of Entomology in coöperation with the Bussey Institution of Harvard University. (Bussey Institution No. 110.) 